\title{
Discussion
}

on a paper published in the

Magazine of Concrete Research

Volume 37, Number 132: September 1985

\section{Application of the highly stressed volume approach to correlated results from different tensile tests of concrete*}

\author{
R. J. Torrent and J. J. Brooks \\ Contribution by Y. S. Jenq and S. P. Shah \\ Northwestern University, Illinois, USA
}

The authors should be commended for their careful and detailed examination of the highly stressed volume approach to correlated results of different tensile tests. From the analysis of their extensive data, they conclude that the HSV approach is not strictly applicable to correlating or predicting tensile strength values from different test methods, i.e., direct tensile, flexural tensile and splitting tensile tests. The present discussion is aimed at pointing out that the recently suggested two parameter fracture mechanics model ${ }^{(1-3)}$ can predict and correlate the different tensile strength calculated using different testing methods as observed by the authors.

\section{THE PROPOSED MODEL}

When a concrete structure/specimen is subjected to an external tensile loading, microcracks will occur at the cement-aggregate interfaces and around entrapped air voids. As the load starts increasing, some of the microcracks will grow and connect with each other and form a larger macrocrack. However, some of the microcracks will be arrested by aggregate or air void. The connecting and arresting processes of microcracks are complex and time-dependent. When the applied load reaches the critical load, one of the macrocracks

\footnotetext{
* Pages 175 to 184 of MCR 132.
}

(the one which has the highest stress intensity factor) starts propagating at constant value of critical stress intensity factor ( $K_{\mathrm{Ic}}^{\mathrm{s}}$ in the global sense). Depending upon the loading configuration, the critical load may not be the peak load and a second crack may be generated. Assuming that the critical load is the peak load (this is true for all three types of tests discussed here), then only one main crack will propagate throughout the structure (for all the other microcracks will be in unloading condition), and the complete loading history will be dominated by this single crack. To characterize the behaviour of this main crack, critical stress intensity factors $\left(K_{\mathrm{Ic}}^{\mathrm{s}}\right)$ and critical crack tip opening displacement $\left(C T O D_{c}\right)$ are proposed to be the fracture criteria.

Linear elastic fracture mechanics can be used to explain the size and the geometry dependency of the test results for brittle materials. For example, if it is assumed that tensile strength is governed by a single parameter such as $K_{\text {Ic }}$ (critical stress intensity factor), then it can be shown that the larger the size of the specimen (in other words the size of the critical flaw), the smaller will be the apparent, measured tensile strength. This assumes that the value of $K_{\mathrm{Ic}}$ is a material parameter, independent of specimen size and geometry. However, the results of the tests conducted by very many investigators show that a single para- 
meter description is not valid for concrete ${ }^{(4)}$. This is due to the nonlinear crack growth that precedes the attainment of critical load and due to the frictional interlock that may exist at the cracked surface. The writers have developed a simple nonlinear-elastic fracture mechanic model to account for these effects. A pre-existing crack of length $a_{\mathrm{o}}$ is assumed to critically propagate when it reaches an effective Griffith crack length $a$ (Figure I). This effective critical length is defined by two parameters: critical opening displacement at the initial crack tip $\left(C T O D_{\mathrm{c}}\right)$ and the critical stress intensity factor (termed $K_{\mathrm{Ic}}^{\mathrm{s}}$ to distinguish from the classical definition). These two material parameters can be calculated, for example, from notchedbeam tests and have been shown to be independent of the size of the beams ${ }^{(1)}$.

Based on the two-parameter fracture model, it is possible to calculate the peak tensile load of structures with different geometries if the failure mechanism is known. It is assumed that a crack will initiate at the point and perpendicular to the direction where the principle tensile stress is maximum. A material length $(Q)$ is used to normalize the numerical results and can be expressed in terms of $E$ (Young's modulus), $K_{\mathrm{Ic}}^{\mathrm{s}}$ and $C T O D_{\mathrm{c}}$ as:

$$
Q=\left(\frac{E \cdot C T O D_{\mathrm{c}}}{K_{\mathrm{lc}}^{\mathrm{s}}}\right)^{2} \ldots \ldots \ldots \ldots
$$

The observed values of $Q$ for concrete, mortar and cement paste range from $100-300 \mathrm{~mm}, 40-150 \mathrm{~mm}$ and $10-50 \mathrm{~mm}$ respectively. In the following section, only the failure mechanisms and theoretical predictions for three-point bending, splitting tensile and direct tensile testing configurations are presented. The calculation procedures are detailed in Reference 1.

\section{THREE-POINT BEND TESTS}

For Three-Point Bend tests, the failure can be

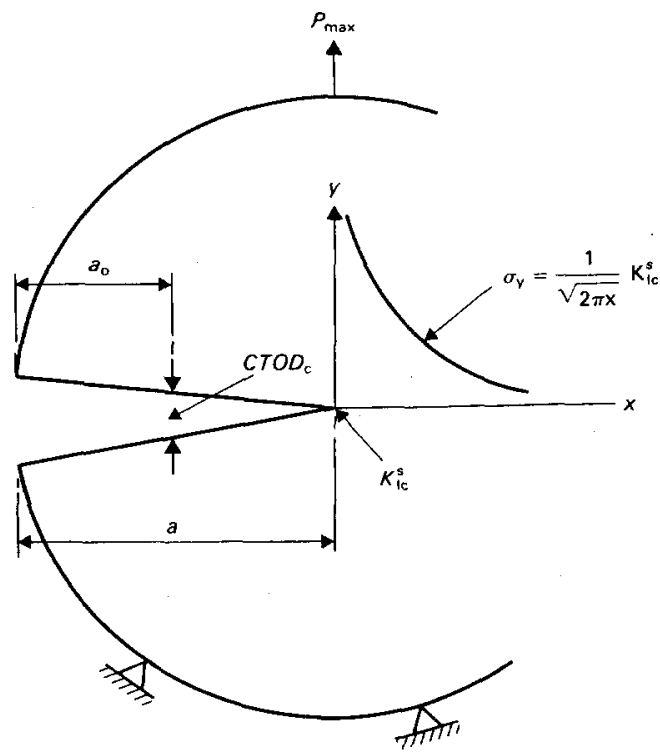

Figure I: Fracture resistance of concrete at peak load.

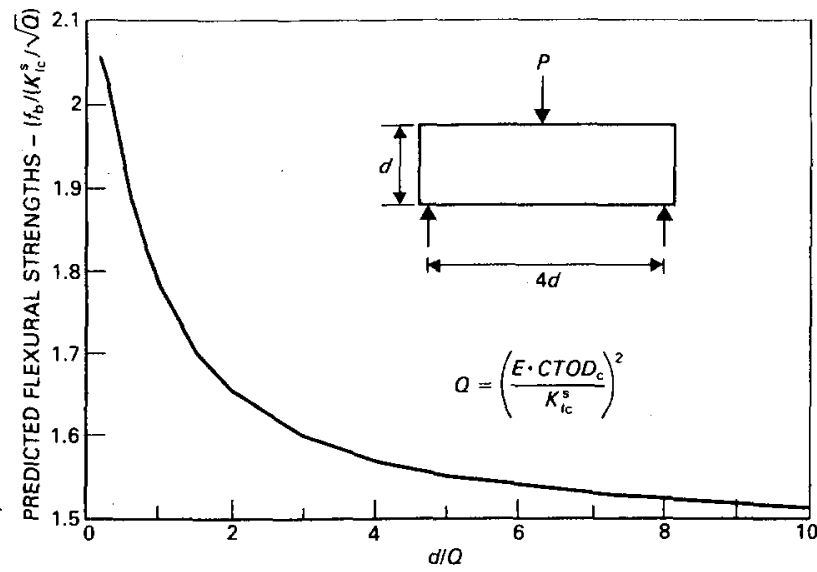

Figure II: Theoretical prediction of Three-Point-Bend strengths.

assumed to initiate at mid-span and bottom of beam and gradually propagate upwards due to the stress gradient effect. Based on this failure mechanism, the theoretical strength of Three-Point-Bend tests $\left(f_{b}\right)$ is found to depend on specimen depth as shown in Figure II. When the specimen depth is larger than $10 Q$, the value of $f_{\mathrm{b}}$ will reach a constant which is equal to $1.4705 K \mathrm{ic} / \sqrt{ } Q$. The above theoretical trend can also be observed from the experimental results reported in the original paper (Tables 5 and 7).

\section{SPLIT-TENSILE TEST}

The splitting tensile tests are usually performed on cylinder or cube specimens. A constant tensile stress zone is present along the diametric loading plane due to the Hertzian contact effect. Thus, it is reasonable to assume that a crack will initiate at the centre of the constant tensile zone. The predicted failure splitting tensile strength $\left(f_{s}\right)$ is plotted in Figure III. It can be seen that the splitting tensile strength reaches a constant value

$$
\left(\frac{4}{\pi} \frac{K_{\mathrm{Ic}}^{\mathrm{s}}}{\sqrt{Q}}\right)
$$

as the cylinder diameter increases. It should be noted

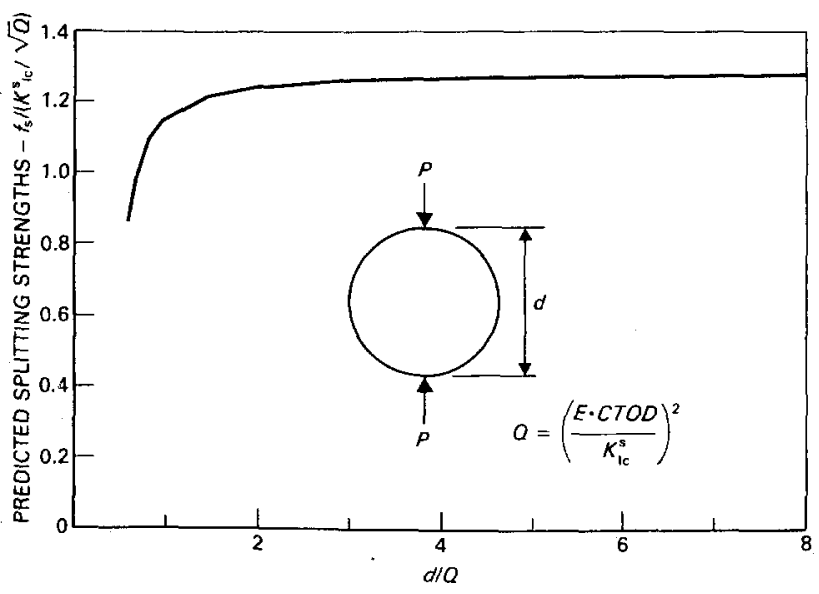

Figure III: Theoretical prediction of splitting-tensile strengths. 
that for small specimens, the Hertzian contact effect may not be exactly the same as the large specimen due to the differences on contact area. For a constant width of the loading strip, the assumption of a concentrated load becomes less accurate for a smaller cylinder. Thus, the observed experimental failure loads for a small specimen may be higher than the theoretically predicted values. Considering specimen size larger than $0.50 Q$, we can find that the flexural strength $\left(f_{\mathrm{b}}\right)$ is always higher than the splitting tensile strengths $\left(f_{s}\right)$. The difference between $f_{\mathrm{b}}$ and $f_{\mathrm{s}}$ ranges from 15 to $75 \%$ depending on the specimen size. This theoretical trend is again observed in the reported experimental results. (See Tables 5 and 7).

\section{DIRECT TENSILE TEST}

The direct tensile test can be predicted using the twoparameter fracture model. If it is assumed that cracks form at the centre of the specimen, symmetrically initiating from the outer edges and progressing inward, then the theoretically calculated tensile strength reaches a constant value

$$
1.4705\left(\frac{K_{\mathrm{Ic}}^{\mathrm{s}}}{\sqrt{Q}}\right)
$$

as soon as the width of the specimen exceeds a value equal to $0.5 Q$ (see the curve labelled $a$ in Figure IV).

In reality, during testing it is difficult to avoid eccentricity. In such a case, the fracture will initiate only at one of the two outer edges. The calculated tensile strength will then depend on the amount of eccentricity, as shown in Figure IV (curves labeled $b$ ). It can be seen from Figure IV, that if there is an eccentricity present, then the results of direct tensile tests will be significantly size dependent and that a variation in eccentricity will give different tensile strength even for identically size specimen. Comparing Figures II and IV it can be seen that the direct tensile

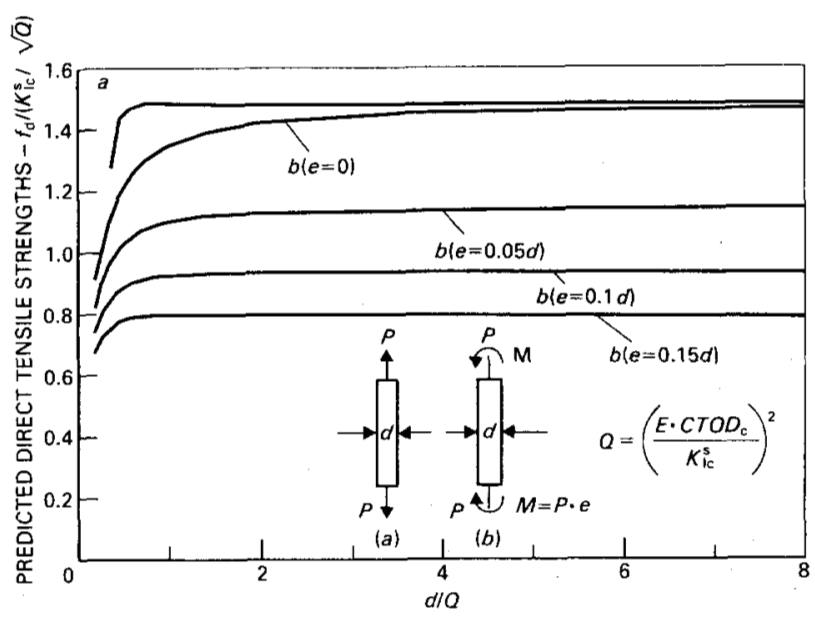

Figure IV: Theoretical prediction of direct-tensile strengths. strength will be; in general, lower than the three point bend test which is also reported by the authors.

The theoretical failure strengths of Three-PointBend tests and Four-Point-Bend tests are about the same using the two-parameter fracture model. However, experimental results reported by the authors show that the strength of Four-Point-Bend tests is always lower than that for Three-Point-Bend tests. This may imply that HSV (or probabilistic) effect does influence the strength of materials. Thus a combination of fracture mechanics and probabilistic approaches may achieve better correlation among various testing methods described by the authors.

\section{REFERENCES}

1. JENQ, Y. S. and SHAH, S. P. Two parameter fracture model for concrete. Journal of Engineering Mechanics (ASCE). October 1985. pp. 1227-1240.

2. JENQ, Y. S. and SHAH, S. P., A fracture toughness criterion for concrete. Engineering Fracture Mechanics. Vol. 21, No. 5. 1985. pp. 1055-1069.

3. JENQ, Y. S., and SHAH, S. P. Crack propagation in fiber-reinforced concrete. Journal of Structural Engineering (ASCE) Vol. 112, No. 1. January 1986. pp. 19-34.

4. SHAH, S. P. (Editor.), Application of fracture mechanics to cementitious composites. Dordrecht. Martinus Nijhoff Publishers, Dordrecht, 1985.

\section{Reply by the authors}

We thank Mr Jenq and Professor Shah for their interest in our paper. In particular we found their last comment on the potentials of a combined approach (fracture mechanics and probabilistic) for achieving a better correlation among various testing methods as very relevant indeed.

Such an approach was attempted by the authors by combining the HSV concept and the Continuous Damage Model. The basic features of that combined approach are summarized below; a more complete analysis can be found in Reference 7 of our paper.

(a) The Continuous Damage Model was used to describe the gradual deterioration of the material as it is strained.

The following damage function was used:

For $\varepsilon \leq \varepsilon_{\mathrm{o}} \quad \omega=\mathrm{o}$

For $\varepsilon>\varepsilon_{\mathrm{o}} \quad \omega=\left(\frac{\varepsilon-\varepsilon_{\mathrm{o}}}{k}\right)^{\mathrm{n}}$

where

$$
\omega=\text { damage factor }=\frac{\Delta A}{A_{\mathrm{o}}}
$$

$\Delta A=$ reduction in cross-sectional area

due to microcracking

$$
A_{\mathrm{o}}=\text { original cross-sectional area }
$$


of a material element

$$
\begin{aligned}
\varepsilon & =\text { applied strain in the element } \\
\varepsilon_{\mathrm{o}} & =\text { threshold strain, below }
\end{aligned}
$$

which no damage occurs (it corresponds to the proportional limit in tension)

$$
k, n=\text { parameters }
$$

The threshold strain $\varepsilon_{\mathrm{o}}$ at the onset of cracking was regarded as size-dependent, according to the following expression:

$\varepsilon_{\mathrm{o}}=\varepsilon_{\mathrm{o}}^{*}+\frac{f_{\mathrm{d}}}{b E}\left[\left(\frac{V}{V^{*}}\right)^{-0.041}-1\right]$

where

$$
\varepsilon_{\mathrm{o}}=\text { threshold strain for a }
$$

specimen having an $\mathrm{HSV}=V$

$$
f_{\mathrm{d}}=\text { direct tensile strength for a }
$$

reference specimen with $\mathrm{HSV}=\mathrm{V}^{*}$

$$
\varepsilon_{\mathrm{o}}^{*}=\text { strain at the proportional }
$$

limit for reference test

$$
\begin{aligned}
& E=\text { modulus of elasticity } \\
& b=\text { parameter obtained from }
\end{aligned}
$$

the Continuous Damage Model,

function of the exponent $n$ in the damage function

The criterion advanced is that the 'size-effect' affects the onset of microcracking $\left(\varepsilon_{\mathrm{o}}\right)$, but that once the fracture process has started, the damage law is identical for all types of test and specimen sizes (parameters $n$ and $k$ are the same).

The following tests were stimulated: Direct Tension, Splitting Test, Three-Point Loading (TPL) and FourPoint Loading (FPL) Bending and, for each test, specimens of sizes corresponding to five different HSV values were considered.
The process of damage was followed by a finite element analysis performed by steps corresponding to increments in the displacements imposed on the specimens.

The following material parameters were used, obtained from experimental results reported in Reference 23 for a concrete of similar characteristics to that tested by the authors:

$$
n=1.23 \quad k=225.10^{-6} \quad E=30.5 \mathrm{kN} / \mathrm{mm}^{2}
$$

Parameters in equation 2 were adopted to fit the experimental direct tensile strength $f_{\mathrm{d}}=3.1 \mathrm{~N} / \mathrm{mm}^{2}$, thus becoming

$$
\left[(\text { microstrains })=60+135\left(\frac{V}{807}\right)^{-0.041}-1\right] \ldots
$$

Figure 5 shows the shape of the curves (Nominal Stress vs Maximum Strain) for different types of test and for the same HSV $=807 \mathrm{~cm}^{3}\left(\varepsilon_{\mathrm{o}}=60.10^{-6}\right)$.

Figure VI shows the experimental results and regression lines presented in Figure V of our original paper, in which the predicted strengths yielded by the combined approach have been included. All the results are predictions but the direct tension test for $\mathrm{HSV}=807$ $\mathrm{cm}^{3}$, was used to adjust equation 3 .

As can be seen the combined approach models satisfactorily both the 'size-effect' and the 'type of testeffect', the latter by simulating the capability of the material to redistribute stresses from overstrained zones of the specimen to less strained zones by microcracking.

The authors are aware that not only the Continuous Damage Model, but any other fracture mechanics

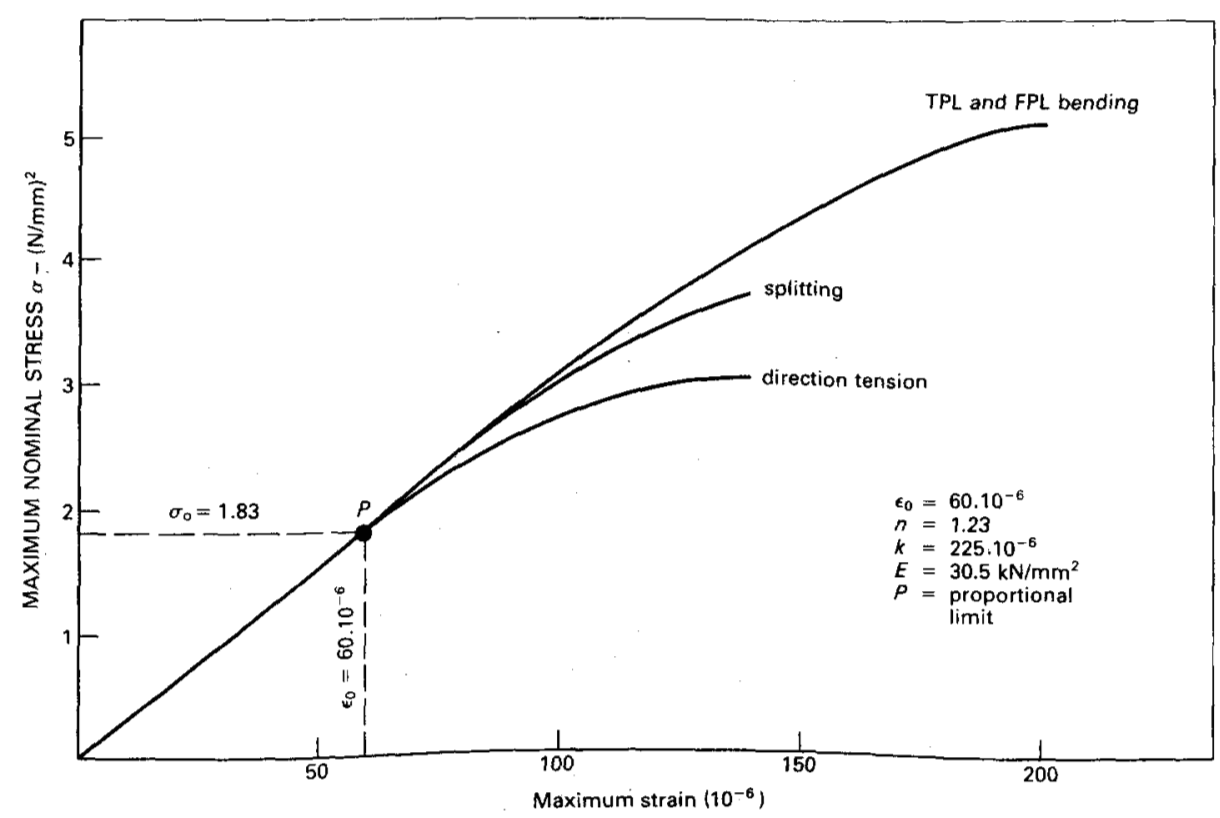

Figure $V: \sigma-\varepsilon$ curve for different types of tensile tests by application of the Continuous Damage Model. 


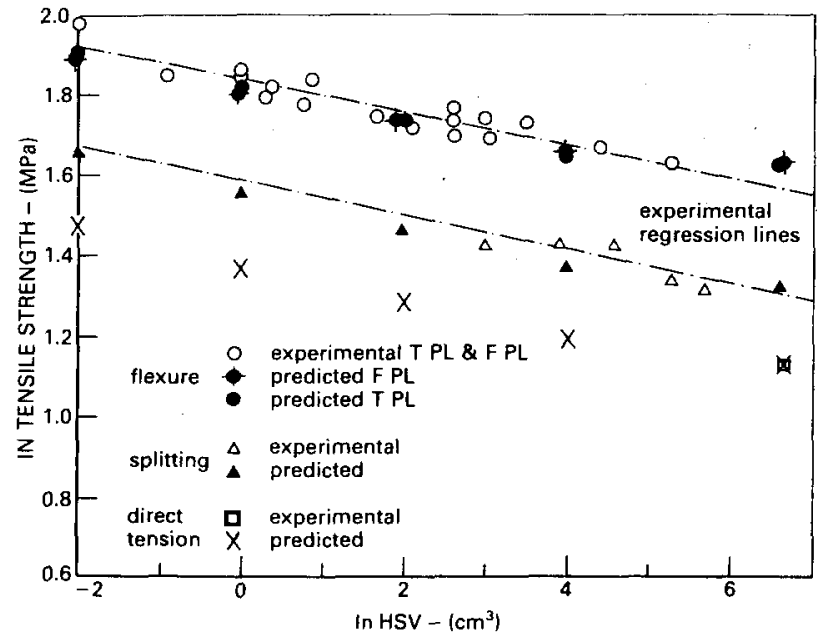

Figure VI: Experimental results of tensile strength for different tests and predicted values (Combined Model). approach which takes into account the gradual loss of load-carrying capacity across the damaging material, could possibly be successfully included in a combined approach. One of them is the 'Two-Parameter Fracture Mechanics Model' proposed by the correspondents; other models worth considering are the 'Fictitious Crack Model' developed by Professor Hillerborg et al. of Lund Institute of Technology, Sweden, and the 'Smeared Crack Model' developed by Professor Bazant $e t$ al. at Northwestern University, USA.

Which of those models is the most suitable to simulate the process of damage in concrete is still an open question.

\section{REFERENCE}

23. KAPLAN, M. F. Strains and stresses of concrete at initiation of cracking and near failure. Journal of the American Concrete Institute Proceedings Vol. 60, No. 7. July 1963. pp. 853-879.

\section{Forthcoming conferences}

\section{9-12 December, 1986 International Seminar on Cement and Allied Building Materials, New Delhi, India.}

The National Council for Cement and Building Materials is organizing this Seminar which will be held at Vigyan Bhavan in New Delhi. It will review the state of the art of cement, lime and allied technologies, highlight recent developments and provide an appropriate forum for the exchange of views between international experts. Included in the programme will be topics covering:

Use of marginal and low grade raw materials

Use of high ash and low calorific value fuels

Durability and performance in construction

Quality considerations

Utilization of industrial, agricultural and other wastes in the manufacture of cement lime and building materials.

Further details from:

\section{S C Rastogi}

Organizing Secretary

National Council for Cement and Building Materials M10 South Extension II Ring Road

New Delhi 101049

India

172

\section{5-21 June 1987 Symposium on Utilization of High Strength Concrete, Stavanger, Norway.}

This Symposium is being organised by the Norwegian Concrete Association; Norwegian Society of Chartered Engineers; the Cement and Concrete Research Institute, the Norwegian Institute of Technology and the Fédération International de la Précontrainte. It will focus on recent investigation, design and construction of advanced structures utilizing high strength concrete.

Further details from:

High Strength Concrete Symposium 1987

c/o NIF-Att. Berg

Kronprinsengt-17

N-0251 Oslo 2

Norway 